\title{
A Comparison of the Prevalence and Related Risk Factors for Post-Partum Depression in Urban and Rural Areas
}

\author{
Mehran Zarghami ${ }^{1,2}$, Fatemeh Abdollahi ${ }^{3,{ }^{*}}$ and Munn-Sann Lye ${ }^{4}$ \\ ${ }^{1}$ Department of Psychiatry, Faculty of Medicine, Mazandaran University of Medical Sciences, Sari, Iran \\ ${ }^{2}$ Psychiatry and Behavioral Sciences Research Center, Addiction Institute, Mazandaran University of Medical Sciences, Sari, Iran \\ ${ }^{3}$ Health Science Research Center, Addiction Institute, Mazandaran University of Medical Sciences, Sari, Iran \\ ${ }^{4}$ Department of Community Health, Faculty of Medicine and Health Sciences, University Putra Malaysia, Seri Kembangan, Malaysia \\ "Corresponding author: Department of Public Health, Faculty of Health, Mazandaran University of Medical Sciences, Sari, Iran. Tel: +98-11333543085, Fax: +98-1133542473, Email: \\ abdollahizagh@gmail.com
}

Received 2017 October 07; Revised 2019 April 07; Accepted 2019 May 25.

\begin{abstract}
Background: Post-partum depression (PPD) is the most prevalent mental problem associated with childbirth. Studies are inconsistent as to whether geographical location is linked with the risk of post-partum depression.

objectives: The current study examined and compared the prevalence and risk factors for post-partum depression in urban and rural areas.

Methods: A prospective cohort study was conducted on 2279 pregnant women in Mazandaran based urban and rural areas. Edinburgh postnatal depression scale (EPDS) and other validated instruments were applied to assess the similarities and differences between depression prevalence rate within 12 postpartum weeks and two women groups' characteristics. Logistic regression model was used to distinguish PPD risk factors in urban and rural residents.

Results: PPD prevalence rate was slightly higher among the urban women (20.1\%) than that of the rural ones (17.8\%) with no significant difference. Although the established PPD risk factors such as prenatal depression and lack of parental self-efficacy were associated with PPD in both groups of women, the rural-specific risk factors such as socio-demographic and health problems were related to PPD in rural areas and social isolation predisposed urban women to PPD.

Conclusions: PPD is a significant health problem among women regardless of their place. The increased PPD risk in each residence is associated with unique risk factors requiring specific interventions.
\end{abstract}

Keywords: Depression, Post-Partum, Prevalence, Risk Factors, Rural, Urban

\section{Background}

The post-partum period is recognized as a time when many women are vulnerable to a variety of emotional symptoms (1). The most prevalent mental or emotional problem associated with childbirth is post-partum depression (PPD); having an adverse effect on the whole family (24). PPD is a cross-cultural phenomenon observed in widely diverse cultures and its outbreak rate was reported as high as $60 \%-80.2 \%$ in the developing world $(1,5)$. Studies comparing PPD among rural and urban women are limited. Villegas et al. reported the prevalence rate ranging from $21.5 \%$ -31.3\% in rural residents of developed and developing counties, respectively (6). An Iranian study revealed PPD as 57.1\% among Isfahan located rural residents (7) in comparison with the reported rate of $20.3 \%-35 \%$ in both rural and urban women $(8,9)$. Although, using different tools or cut-off points may cause this variation.
In Iran, about $30 \%$ of the population lives in rural areas. Hence it seems that PPD is more of a concern than other medical problems for childbearing age women. A number of risk factors have been proposed for PPD development. However, the results are not conclusive (10) and the issue as to whether residence is a risk factor for PPD remains controversial. Some studies reported urban women to be more vulnerable to PPD than those rural dwellers $(11,12)$, while other studies results are inconsistent $(10,13)$.

\section{Objectives}

The women in cities and villages live under different socioeconomic conditions. Consequently, the impact of residence as well as the relation between this and other risk factors on PPD may differ (12). The current study examined the potential impact of related risk factors on PPD's rate and risk in urban and rural areas women. 


\section{Materials and Methods}

The goal of this study as a part of a large longitudinal cohort research is to compare the contribution of probable risk factors to PPD prevalence and risk in urban and rural areas of Mazandaran province, Iran.

There are 16 urban and 213 rural geographic areas in this state. In this study, all 16 cities and 4 urban areas from 4 geographic parts of each city (North, South, West and East) were selected as the study locations. There are 101 and 207 primary health centers (PHCs) in urban and rural areas, respectively, providing services for approximately $98 \%$ of pregnant women in the province. Out of 42000 pregnant women, 9187 (4684 in urban and 4503 in rural) were in their 3rd pregnancy trimester and referred to the clinics for antenatal care during the recruitment period from January to June 2009, as part of the study population. Of this population, 2626 women were eligible and entered the study and of these, 2359 (89.8\%) volunteered and 2279 (96.6\%) completed the initial questionnaires. The final sample which followed the study period from 32 - 42 pregnancy to 12 postpartum weeks $(\mathrm{n}=1982 ; 86.96 \%)$ consisted of 1012 (51.1\%) urban and 970 (48.9\%) rural women with a drop-up rate of 297 (13.03\%). G-power software for logistic regression was used to estimate the sample size (14).

Educated health care practitioners reviewed the households' documents to identify appropriate women based on our inclusion criteria and distributed the questionnaires among eligible women. Literate women aged 16 - 45 years old with gestational age of 32 - 42nd weeks that attended PHCs for prenatal care were recruited in this study. The women under pharmacological treatment for psychiatric problems were excluded from the study. The potential risk factors (indicators) in the 3rd pregnancy trimester and after birth were utilized to estimate the depression risk within 12 post-partum weeks. The participants provided information on the demographics, socio-economic, mental health, abuse history, hormone related factors, social support, life events, marital relationships, complications during pregnancy, delivery and after birth, rituals and customs and postnatal parenting self-efficacy using the standardized questionnaires explained in detail somewhere else (15-17). Validated instruments that were used in this study included the premenstrual syndrome questionnaire (PMSQ) (18), social support appraisals scale (SSA) (19), network orientation scale (NOS) (20), general health questionnaire (GHQ-28) (21), marital inventory (ENRICH) (22), life events rating scale (LERS) (23), parental expectation survey (PES) (24), Edinburgh postnatal depression scale (EPDS) (25) and a researchers design questionnaire that include demographic characteristics, information on mental health, hormone related conditions, abuse history, obstetric and gynecological data and rituals and customs after childbirth.

Mental health status was evaluated employing EPDS (25) that includes 10 mood related items. The mothers are scored from zero to three ("no, not at all" to "yes, quite often") according to the symptoms' severity during the previous week. The total score is calculated by computing the scores for each of the 10 items with seven of them being scored reversely (26). A score more than 12 was considered as the probability of a woman with PPD in Iran (27). The study was verified by the Medical Ethics Committees of University Putra Malaysia (UPM) (grant number 200945) and Mazandaran University of Medical Sciences (MAZUMS) in Iran (grant number 88-20). The women gave written consent at the time of entering the study.

The data was exported to IBM-SPSS V. 20. To determine the similarities and differences between the urban and rural groups in terms of related variables, the data was analyzed using chi-square for the categories and independent sample $t$-test for continuous variables. The prevalence of depression at each event was calculated and compared between the urban and rural residing women.

To predict the association between the potential risk factors and PPD within 12 post-partum weeks, binary logistic regression analysis was applied generating the corresponding odds ratios (OR) coupled with $95 \%$ confidence intervals (CI). Then in the multiple logistic regression model, the variables with $P$ values less than 0.25 in univariate analysis as well as those variables significantly different between the urban and rural women resulting from chisquare and $t$-tests, were forced in the model using the rural group as the referent category. We applied this model once for the entire sample and again among the urban and rural women separately. Hierarchical multiple logistic regression model was used to see which variables came out significant. Based on the literature review and the preliminary exploratory method, the variables were entered in sequential order: the psychological, sociological, sociodemographic hormone-related, cultural and obstetric and gynecological factors, respectively.

\section{Results}

Out of 2279 women who agreed to take part in the study, 1982 followed the study until 12 post-partum weeks. A comparison was conducted between the women who followed (86.96\%) and the ones who didn't (13.03\%) with no significant differences between these two groups in terms of the average age ( $25.05 \mathrm{vs.} 25.7$ years), the education of the women and that of their husbands, total family income as well as the previous PPD. 
The mean age and marriage time age of the women was $25.05 \pm 5.20$ and $20.52 \pm 4.09$ years, respectively. About two thirds of the women (60\%) had no children and over $90 \%$ of them breastfed exclusively during three post-partum months. Half of the women (48.90\%) were recruited from rural PHCs, and the rest (51.1\%) from urban PHCs. Of the urban women, 54.9\% lived in nuclear families, 60\% lived in rented premises, and were of higher socio-economic status compared to the rural ones [income (334827.07 vs. 297500.00 Rials/mo), educational level (11.23 vs. 8.98 years), and employment (73.3\% vs. $26.3 \%$ )]. Their husbands were also more employed as governmental servants compared with the rural men working as farmers (67.6\% vs. $79.5 \%$ ). The urban women reported more medical diseases (57.9\%), were more likely to deliver in private hospitals (65\%) and had lower participation in health educational programs during pregnancy (48.8\%) compared to the rural dwellers. Moreover, urban women were more likely to report lower health status based on GHQ (54.7\%), more pregnancy period induced anxiety (54.7\%), irritable mood before menstruation (60.3\%) and mood instability in puberty (59.1\%) in comparison with those of the rural areas. Tables 1 and 2 described and compared the characteristics of rural and urban dwelling women. The mean differences of the continuous variables in the two groups of women is illustrated in Table 3.

Depression during 32 - 42 weeks of pregnancy and 12 post-partum weeks based on EPDS scores was more common in the urban women compared to the rural ones with no significant difference between the two groups as Table 4 depicts.

In a separate multiple logistic regression model, depression during 32 - 42 weeks of pregnancy based on EPDS and parenting self-efficacy from PES have been the significant factors to predict PPD in both urban and rural women. Moreover, urban and rural-specific risk factors of depression which applied to the women after their delivery in the two groups are seen in Table 5. As Table 5 shows, greater social isolation based on NOS in urban women and lower general health based on GHQ, living in an extended family, lower educational level and more medical diseases in rural women have been the significant factors to predict PPD.

\section{Discussion}

The answer to the question, i.e., whether geographic location is a protective factor for PPD development was evaluated. This study found no significant difference in PPD rate in the urban and rural women (20.1\% vs. $17.6 \%)$. It seems that in our study, maybe other factors are more significant than living place to predict PPD.
The studies comparing PPD prevalence rate among the rural and urban women living in developed countries, such as Australia, reported higher rates of PPD in the rural (8.5\%) compared to urban (6.6\%) women with no significant difference $(12,13)$. A PPD-related study comparison in the two groups of women in a developing country such as Lebanon, reported higher rate of PPD among the rural women (26\%) to the urban ones (16\%) (28). In a systematic review, PPD prevalence was higher among the rural women than the urban ones, especially in developing countries (21.5\% in developed countries rural women vs. $31.3 \%$ in developing countries' rural ones) (6). Low socioeconomic status such as low income and low education as well as poor life quality and lack of mental health services may contribute to the onset of mental illness among rural women $(6,29,30)$.

Comparisons between the rural and urban women's characteristics yielded some differences between the two groups of women. Socio-economic and health status was somewhat higher in the urban women than that of the rural ones, which could be attributed to poverty in rural areas. In turn, urban women suffer more from social isolation that could be related to urbanization consequences in urban residence. A study highlights the importance of social relations rather than social conditions in determining depression in urban Pakistani pregnant women (31). Family structure reform leading to diminished supportive care proved as a significant determinant of PPD (32).

Regarding PPD predicting factors, women from both rural and urban areas shared common PPD risk factors including depression during 32 - 42 weeks of pregnancy and low parenting self-efficacy. Antenatal depression was the strongest predictor of PPD development in numerous studies $(33,34)$. In a research in rural Tamil Nadu, India, nearly a half of PPD patients reported previous episodes taking place during or prior to pregnancy (35). The continued contacts health care providers have with mothers during pregnancy create an excellent opportunity for screening and intervention when required.

This study is compatible with several other studies in demonstrating that low parenting self-efficacy plays significant roles in PPD development (36-38). Child care induced stress was discovered more in Taiwanese women receiving higher scores in EPDS during post-partum period (39). It is possible that these women were not prepared for mothering during their pregnancy (40).

Separate multiple analyses identified additional PPD risk factors in urban women such as the perceived social isolation, and in rural women, lower general health status based on GHQ, living in an extended family, lower education, experiencing medical diseases and gestational diabetics. Differences in PPD risk factors between the rural 


\begin{tabular}{|c|c|c|c|}
\hline Variables & $\operatorname{Urban}(\mathrm{N}=1012)$ & $\operatorname{Rural}(N=970)$ & PValue \\
\hline Family structure & & & 0.001 \\
\hline Extended & $227(41.1)$ & $325(58.9)$ & \\
\hline Nuclear & $785(54.9)$ & $645(50.1)$ & \\
\hline Housing & & & 0.001 \\
\hline Renter & $509(60)$ & $274(35)$ & \\
\hline House owner & $503(42)$ & $696(58)$ & \\
\hline Employed & & & 0.001 \\
\hline Housewife + student & $925(49.6)$ & $939(50.4)$ & \\
\hline Employment & $87(73.3)$ & $31(26.3)$ & \\
\hline Husband employed & & & 0.001 \\
\hline Business & $678(50.1)$ & $674(49.9)$ & \\
\hline Farmer & $27(20.5)$ & $105(79.5)$ & \\
\hline Jobholder & $189(67.6)$ & $90(32.3)$ & \\
\hline Others & $118(53.9)$ & $101(46.1)$ & \\
\hline Medical diseases & $143(57.9)$ & $104(42.1)$ & 0.01 \\
\hline Gestational diabetes & $40(48.4)$ & $43(51.8)$ & 0.33 \\
\hline Gestational hypertension & $41(49.4)$ & $42(50.6)$ & 0.42 \\
\hline Recurrent urinary infection & $123(51.5)$ & $116(48.5)$ & 0.47 \\
\hline Morning sickness & $83(51.6)$ & $78(48.4)$ & 0.48 \\
\hline Back pain & $64(56.6)$ & $49(43.4)$ & 0.12 \\
\hline Planned pregnancy & $786(50.2)$ & $780(49.8)$ & 0.11 \\
\hline Participating in Health Education Program & $809(48.6)$ & $857(51.4)$ & 0.001 \\
\hline Delivery mode & & & 0.19 \\
\hline Cesarean section & $203(53.3)$ & $178(46.7)$ & \\
\hline Vaginal & $524(50.5)$ & $511(49.50$ & \\
\hline Place of delivery & & & 0.001 \\
\hline Private hospital & $208(65)$ & $112(35)$ & \\
\hline Public hospital & $803(48.4)$ & $855(51.6)$ & \\
\hline Sex of the baby & & & 0.28 \\
\hline Male & $510(51.4)$ & $483(48.6)$ & \\
\hline Female & $501(50.9)$ & $484(49.1)$ & \\
\hline Time delivery & & & 0.13 \\
\hline$<37$ & $186(53.9)$ & $159(46.1)$ & \\
\hline$\geq 37$ & $823(50.5)$ & $808(49.5)$ & \\
\hline Neonatal morbidity & $135(54.2)$ & $114(45.8)$ & 0.16 \\
\hline Puerperal complication & $305(51.4)$ & $288(48.6)$ & 0.44 \\
\hline Breastfeeding status for three months & & & 0.06 \\
\hline Exclusive breastfeeding & $894(50.5)$ & $876(49.5)$ & \\
\hline $\begin{array}{l}\text { Bottle feeding or mix feeding (breastfeeding and bottle } \\
\text { feeding) }\end{array}$ & $108(56.5)$ & $83(43.5)$ & \\
\hline
\end{tabular}

${ }^{\mathrm{a}}$ Values are expressed as No. (\%).

and urban women may be due to different socio-economic and environmental situations in these two groups of women (6).

Although there was no significant difference in the support level the rural and urban women received, social isolation was proved as a significant factor to predict PPD among the urban women. Social isolation also revealed a strong association with PPD in developed nations' women such as Denmark, Italy and Canada $(36,41,42)$ compared with the women not reporting feelings of social isolation. In recent decades, fast demographic and socio-economic reforms have been experienced by the societies in developing countries and traditional family structure reforms and diminished supportive care have turned as the poten- 


\begin{tabular}{|c|c|c|c|}
\hline Variables & $\operatorname{Urban}(\mathrm{N}=1012)$ & $\operatorname{Rural}(\mathbf{N}=970)$ & PValue \\
\hline Depression during 32 - 42 weeks of pregnancy based on EPDS & & & 0.06 \\
\hline$\leq 12$ & $782(50.1)$ & $778(49.9)$ & \\
\hline$>12$ & $230(54.5)$ & $192(45.5)$ & \\
\hline General health status from GHQ scores & & & 0.002 \\
\hline Good (21 or less) & $484(54.7)$ & $401(45.3)$ & \\
\hline Weak (more than 21) & $528(48.1)$ & $569(54.9)$ & \\
\hline Previous post-partum depression & $34(54.8)$ & $28(45.2)$ & 0.28 \\
\hline Depression in the 1st and 2nd trimesters of pregnancy & $133(51.4)$ & $126(48.6)$ & 0.48 \\
\hline Anxiety in pregnancy & $509(54.7)$ & $421(45.3)$ & 0.001 \\
\hline Irritable mood before menstruation/pre-menstruation & $210(60.3)$ & $138(39.7)$ & 0.001 \\
\hline Irritable mood & $133(59.1)$ & $92(40.9)$ & 0.006 \\
\hline Puberty mood instability & $254(45.4)$ & $306(54.6)$ & 0.26 \\
\hline
\end{tabular}

${ }^{\mathrm{a}}$ Values are expressed as No. (\%).

\begin{tabular}{|c|c|c|c|}
\hline Variables & Urban $(N=1012)$ & $\operatorname{Rural}(\mathbf{N}=970)$ & PValue \\
\hline Age, $y$ & $26.23(5.23)$ & $25.86(5.17)$ & 0.62 \\
\hline Marriage time age, $y$ & $20.75(4.20)$ & $20.27(3.97)$ & 0.26 \\
\hline Parity & $0.48(0.66)$ & $0.51(0.68)$ & 0.10 \\
\hline Education, $y$ & $11.23(3.01)$ & $9.98(2.99)$ & 0.001 \\
\hline Husband education, $y$ & $11.02(3.15)$ & $9.88(3.18)$ & 0.11 \\
\hline Household Income, Tomans, monthly ${ }^{b}$ & $334827.07(162387.72)$ & $297500.00(136071.45)$ & 0.001 \\
\hline Depression during 32-42 weeks of pregnancy based on EPDS & $8.86(4.93)$ & $8.38(4.86)$ & 0.79 \\
\hline Depression within 12 post-partum weeks based on EPDS & $8.53(4.97)$ & $8.08(4.98)$ & 0.69 \\
\hline General health status from GHQ & $22.85(9.22)$ & $21.30(9.06)$ & 0.30 \\
\hline Social support during pregnancy from SSA & $47.87(5.40)$ & $47.37(5.02)$ & 0.06 \\
\hline Social isolation during pregnancy from NOS & $48.34(4.47)$ & $47.88(4.20)$ & 0.06 \\
\hline Marital satisfaction during pregnancy from MS & $24.56(4.21)$ & $24.88(3.70)$ & 0.01 \\
\hline Parenting self-efficacy from PES & $7.84(1.50)$ & $7.94(1.53)$ & 0.37 \\
\hline Number of life events from LERs & $3.24(2.96)$ & $3.00(3.01)$ & 0.29 \\
\hline Abuse victim or abuse witness & $0.68(2.11)$ & $0.68(2.03)$ & 0.93 \\
\hline Number of ritual practices during postnatal period ${ }^{c}$ & $14.11(4.15)$ & $14.18(3.80)$ & 0.08 \\
\hline \multicolumn{4}{|c|}{$\begin{array}{l}\text { Abbreviations: Abused, refers to all forms of abuse including physical, emotional, sexual abuse, and negligence; EPDS, Edinburgh postnatal depression scale; GHQ, } \\
\text { general health questionnaire; LERS: life event rating scale; MS, ENRICH marital inventory; NOS, network orientation scale; PES, parental expectation survey; SSA, social } \\
\text { support appraisal. } \\
\text { a Values are expressed as mean (SD). } \\
\text { b Tomans; } 10 \text { Rials; ( } 1 \text { Tomans }=0.01 \text { USD). } \\
\text { cThe number of ritual practices was ranging from } 0 \text { to } 27 \text { where higher score show greater practice of rituals. }\end{array}$} \\
\hline Variables & Urban $(N=1012)$ & $\operatorname{Rural}(\mathbf{N}=970)$ & PValue \\
\hline Depression during 32-42 weeks pregnancy based on EPDS & $230(22.7)$ & $192(19.8)$ & 0.06 \\
\hline Twelve post-partum weeks depression based on EPDS & $203(20.1)$ & $173(17.8)$ & 0.11 \\
\hline
\end{tabular}

${ }^{\mathrm{a}}$ Values are expressed as No. (\%).

tial determinants of PPD $(32,43)$. This reform has probably led women to turn to friends rather than to family members for support and in the cases when a woman has had no affective bonds outside the family or when such bonds have been weak, depressed mood has increased.

Surprisingly, our rural sample data analysis suggested that rural women living in extended families have been more predisposed to PPD. It is possible that in rural 


\begin{tabular}{|c|c|c|c|c|c|c|}
\hline \multirow{2}{*}{ Variables } & \multicolumn{3}{|c|}{ Urban $(N=1012)$} & \multicolumn{3}{|c|}{$\operatorname{Rural}(\mathbf{N}=\mathbf{9 7 0})$} \\
\hline & Odds Ratio & 95\% CI & PValue & Odds Ratio & 95\% CI & P Value \\
\hline Depression during 32-42 weeks of pregnancy based on EPDS & 1.26 & $1.20-1.32$ & 0.001 & 1.28 & $1.22-1.34$ & 0.001 \\
\hline Parenting self-efficacy from PES & 0.88 & $1.00-1.09$ & 0.02 & 0.81 & $0.72-0.92$ & 0.001 \\
\hline Social isolation during pregnancy from NOS & 1.04 & $0.79-0.98$ & 0.02 & - & - & - \\
\hline General health status from GHQ & - & - & - & 1.03 & $1.00-1.05$ & 0.006 \\
\hline Family structure & - & - & - & 0.59 & $0.39-0.88$ & 0.01 \\
\hline Education & - & - & - & 0.91 & $0.85-0.97$ & 0.006 \\
\hline Medical diseases & - & - & - & 1.99 & $1.03-3.85$ & 0.04 \\
\hline Gestational diabetes & - & - & - & 0.42 & $0.19-0.95$ & 0.03 \\
\hline
\end{tabular}

women, in-laws conflict especially with their mothers-inlaw is an important factor in determining post-partum emotional adjustment failure, which leads to depression (44). Another issue requiring further investigation is the satisfaction regarding the support experienced. In a study conducted in Mexico, the results suggested that the women with unfulfilled desire for support and paradoxically, those with excessive support felt isolated much more and thus are more vulnerable to PPD (45).

Concerning the relationship between education and PPD in rural women, in line with other rural studies in Iran (7), our study derived results demonstrated a positive one. However, the studies on the relationship between education and PPD often generate conflicting findings with positive $(34,46)$ and negative $(42,47)$ results in both developed and developing countries (e.g. Pakistan, New Mexico, Turkey, Italy, Japan). It is difficult to contextualize and interpret educational levels because of a close relationship between education and employment, income and socioeconomic status (41). Further studies are required to prove this relationship.

In agreement with a Lebanese research, medical illhealth has also been associated with PPD solely in the rural women (28). Medical diseases may change or disturb neurotransmitter action or turn into the stressor itself, thus making them vulnerable to depression (28). The possible reason behind discovering no association between medical problems and PPD in urban women could be attributed to the greater access these women have to health facilities and higher socio-economic level of the urban sample in our study. The women with low socio-economic-status (SES) compared to medical, social, and emotional support have disadvantages which may lead to stress and thus need extra resources in order to cope with $(48,49)$.

This study results indicated that the prevalence rate among urban women was slightly lower than that of the rural ones. Also, this study verified the established PPD risk factors' relationship with urban and rural women including the psychosocial factors. Additional urban and rural-specific factors contributing to PPD development include social isolation for urban women and medical illhealth and low social status for rural women requiring specific intervention. While urban area-dwelling women may benefit from support, public health programs should target rural women to improve their lifestyles and increase their socio-economic status. PPD screening by health care providers taking the distinguishing factors among rural and urban women into consideration will provide significant psychological benefits for the women.

Some caution has to be taken in this study using selfreported screening tools without being diagnostically confirmed. However, EPDS is a screening tool with the best sensitivity and specificity.

\section{Acknowledgments}

This study was supported by UPM (grant number 200945) and MAZUMS (grant number 88-20). We are grateful of health care provider facilities for collect the data and all the women who participated in this study.

\section{Footnotes}

Authors' Contribution: Fatemeh Abdollahi conceived and designed the evaluation, collected the clinical data, interpreted them, performed the statistical analysis and drafted the manuscript. Munn-Sann Lye participated in designing the evaluation, and helped in interpretation of the clinical data. Mehran Zarghami participated in designing the evaluation, re-evaluated the clinical data, and revised the manuscript. All authors read and approved the final manuscript.

Clinical Trial Registration Code: It is not declared by the authores. 
Conflict of Interests: The authors declare that there is no conflict of interest.

Ethical Approval: The study was verified by the Medical Ethics Committees of University Putra Malaysia (UPM) and Mazandaran University of Medical Sciences (MAZUMS).

Funding/Support: This study was supported by UPM (grant number 200945) and MAZUMS (grant number 8820).

\section{References}

1. Norhayati MN, Hazlina NH, Asrenee AR, Emilin WM. Magnitude and risk factors for postpartum symptoms: A literature review. J Affect Disord. 2015;175:34-52. doi: 10.1016/j.jad.2014.12.041. [PubMed: 25590764].

2. Lilja G, Edhborg M, Nissen E. Depressive mood in women at childbirth predicts their mood and relationship with infant and partner during the first year postpartum. Scand J Caring Sci.2012;26(2):245-53. doi: 10.1111/j.1471-6712.2011.00925.x. [PubMed: 21950600].

3. Earls MF, Committee on Psychosocial Aspects of C, Family Health American Academy of P. Incorporating recognition and management of perinatal and postpartum depression into pediatric practice. Pediatrics. 2010;126(5):1032-9. doi: 10.1542/peds.2010-2348. [PubMed: 20974776].

4. Farias-Antunez S, Xavier MO, Santos IS. Effect of maternal postpartum depression on offspring's growth. J Affect Disord. 2018;228:143-52. doi: 10.1016/j.jad.2017.12.013. [PubMed: 29248820].

5. Klainin P, Arthur DG. Postpartum depression in Asian cultures: A literature review. Int J Nurs Stud. 2009;46(10):1355-73. doi: 10.1016/j.ijnurstu.2009.02.012. [PubMed:19327773].

6. Villegas L, McKay K, Dennis CL, Ross LE. Postpartum depression among rural women from developed and developing countries: A systematic review. J Rural Health. 2011;27(3):278-88. doi: 10.1111/j.17480361.2010.00339.x. [PubMed: 21729155].

7. Kheirabadi GR, Maracy MR, Barekatain M, Salehi M, Sadri GH, Kelishadi M, et al. Risk factors of postpartum depression in rural areas of Isfahan province, Iran. Arch Iran Med. 2009;12(5):461-7. [PubMed: 19722767].

8. Najafi K, Avakh F, Nazifi F, Sabrkonandeh S. [Prevalence of postpartum depression in Alzahra Hospital in Rasht in 2004].J Guilan Univ Med Sci. 2006;15(59):97-105. Persian.

9. Ghafarinezhad A, Joybari F, Poya F. [Prevalence of postpartum depression in Kerman]. Iran JPsychiatry Clin Psychol.2000;5(1,2):24-9. Persian.

10. Robertson E, Grace S, Wallington T, Stewart DE. Antenatal risk factors for postpartum depression: A synthesis of recent literature. Gen Hosp Psychiatry. 2004;26(4):289-95. doi: 10.1016/j.genhosppsych.2004.02.006. [PubMed: 15234824].

11. Vigod SN, Tarasoff LA, Bryja B, Dennis CL, Yudin MH, Ross LE. Relation between place of residence and postpartum depression. CMAJ. 2013;185(13):1129-35. doi: 10.1503/cmaj.122028. [PubMed: 23922346]. [PubMed Central: PMC3778469].

12. Bilszta JL, Gu YZ, Meyer D, Buist AE. A geographic comparison of the prevalence and risk factors for postnatal depression in an Australian population. Aust N Z J Public Health. 2008;32(5):424-30. doi: 10.1111/j.1753-6405.2008.00274.x. [PubMed: 18959545].

13. Johnstone SJ, Boyce PM, Hickey AR, Morris-Yatees AD, Harris MG. Obstetric risk factors for postnatal depression in urban and rural community samples. Aust N Z J Psychiatry. 2001;35(1):69-74. doi: 10.1046/j.1440-1614.2001.00862.x. [PubMed: 11270460].

14. Demidenko E. Sample size determination for logistic regression revisited. Stat Med. 2007;26(18):3385-97. doi: 10.1002/sim.2771. [PubMed: 17149799].

15. Abdollahi F, Zarghami M, Azhar MZ, Sazlina SG, Lye MS. Predictors and incidence of post-partum depression: A longitudinal cohort study. J Obstet Gynaecol Res. 2014;40(12):2191-200. doi: 10.1111/jog.12471. [PubMed: 25132641].

16. Abdollahi F, Rohani S, Sazlina GS, Zarghami M, Azhar MZ, Lye MS, et al. Bio-psycho-socio-demographic and obstetric predictors of postpartum depression in pregnancy: A prospective cohort study. Iran J Psychiatry Behav Sci. 2014;8(2):11-21. [PubMed: 25053953]. [PubMed Central: PMC4105600].

17. Abdollahi F, Sazlina SG, Zain AM, Zarghami M, Asghari Jafarabadi M, Lye MS. Postpartum depression and psycho-socio-demographic predictors. Asia Pac Psychiatry. 2014;6(4):425-34. doi: 10.1111/appy.12152. [PubMed: 25262614].

18. Mortola JF, Girton L, Beck L, Yen SS. Diagnosis of premenstrual syndrome by a simple, prospective, and reliable instrument: The calendar of premenstrual experiences. Obstet Gynecol. 1990;76(2):302-7. [PubMed: 2371035].

19. Vaux A, Phillips J, Holly L, Thomson B, Williams D, Stewart D. The social support appraisals (SS-A) scale: Studies of reliability and validity. Am J Commun Psychol.1986;14(2):195-218. doi:10.1007/bfo0911821.

20. Vaux A. Factor structure of the network orientation scale.Psycholl Rep. 2016;57(3_suppl):1181. doi: 10.2466/pro.1985.57.3f.1181.

21. Goldberg D. The detection of psychiatric illness by questionnaire. London: Oxford University Press; 1972.

22. Olson DH, Fournier DGM, Druckman JM, McCubbin HI, Barnes H, Larsen A, et al. ENRICH: Enriching and nurturing relationship issues, communication and happiness 1982. Family inventories Family social sciences. St Paul, Minnesota: University of Minnesota; 1983.

23. Holmes TH, Rahe RH. The social readjustment rating scale.JPsychosom Res. 1967;11(2):213-8. [PubMed: 6059863].

24. Reece SM. The parent expectations survey: A measure of perceived self-efficacy. Clin Nurs Res. 1992;1(4):336-46. doi: 10.1177/105477389200100404. [PubMed: 1483137].

25. Cox JL, Holden JM, Sagovsky R. Detection of postnatal depression. Development of the 10-item Edinburgh Postnatal Depression Scale. Br J Psychiatry. 1987;150:782-6. [PubMed:3651732].

26. Beck CT, Gable RK. Postpartum depression screening scale: Development and psychometric testing. Nurs Res. 2000;49(5):272-82. [PubMed: 11009122].

27. Namazi S. [Risk factors of postpartum depression]. J Hormozgan Univ Med Sci. 2000;3(1):17-24. Persian.

28. Chaaya M, Campbell OM, El Kak F, Shaar D, Harb H, Kaddour A. Postpartum depression: Prevalence and determinants in Lebanon. Arch Womens Ment Health. 2002;5(2):65-72. doi: 10.1007/s00737-002-0140-8. [PubMed: 12510201]. [PubMed Central: PMC1457112].

29. Mollard E, Hudson DB, Ford A, Pullen C. An integrative review of postpartum depression in rural U.S. communities. Arch Psychiatr Nurs. 2016;30(3):418-24. doi: 10.1016/j.apnu.2015.12.003. [PubMed: 27256951].

30. Kim Y, Dee V. Sociodemographic and obstetric factors related to symptoms of postpartum depression in hispanic women in rural California. J Obstet Gynecol Neonatal Nurs. 2018;47(1):23-31. doi: 10.1016/j.jogn.2017.11.012. [PubMed: 29221670].

31. Kazi A, Fatmi Z, Hatcher J, Kadir MM, Niaz U, Wasserman GA. Social environment and depression among pregnant women in urban areas of Pakistan: Importance of social relations. Soc Sci Med.2006;63(6):146676. doi: 10.1016/j.socscimed.2006.05.019. [PubMed: 16797813].

32. Husain N, Bevc I, Husain M, Chaudhry IB, Atif N, Rahman A. Prevalence and social correlates of postnatal depression in a low income country. Arch Womens Ment Health. 2006;9(4):197-202. doi:10.1007/s00737-0060129-9. [PubMed: 16633740].

33. McCoy SJ, Beal JM, Shipman SB, Payton ME, Watson GH. Risk factors for postpartum depression: A retrospective investigation at 4weeks postnatal and a review of the literature. J Am Osteopath Assoc. 2006;106(4):193-8. [PubMed:16627773].

34. Mancini F, Carlson C, Albers L. Use of the postpartum depression screening scale in a collaborative obstetric practice. J Midwifery 
Womens Health. 2007;52(5):429-34. doi: 10.1016/j.jmwh.2007.03.007. [PubMed: 17826704].

35. Chandran M, Tharyan P, Muliyil J, Abraham S. Post-partum depression in a cohort of women from a rural area of Tamil Nadu, India. Incidence and risk factors. Br J Psychiatry. 2002;181(6):499-504. [PubMed: 12456520].

36. Birkeland R, Thompson JK, Phares V. Adolescent motherhood and postpartum depression. J Clin Child Adolesc Psychol. 2005;34(2):292300. doi:10.1207/s15374424jccp3402_8. [PubMed: 15901229].

37. Records K, Rice MJ. Lifetime physical and sexual abuse and the risk for depression symptoms in the first 8 months after birth. J Psychosom Obstet Gynaecol. 2009;30(3):181-90. doi: 10.1080/01674820903178121. [PubMed: 19728219].

38. DeMaris A, Mahoney A. The perception of fairness in infant care and mothers' postpartum depression. Soc Sci Med. 2017;190:199-206. doi: 10.1016/j.socscimed.2017.08.030. [PubMed: 28866473].

39. Huang YC, Mathers N. Postnatal depression - biological or cultural? A comparative study of postnatal women in the UK and Taiwan.J Adv Nurs. 2001;33(3):279-87. [PubMed: 11251714].

40. Mohammad KI, Gamble J, Creedy DK. Prevalence and factors associated with the development of antenatal and postnatal depression among Jordanian women. Midwifery. 2011;27(6):e238-45. doi: 10.1016/j.midw.2010.10.008. [PubMed: 21130548].

41. Nielsen Forman D, Videbech P, Hedegaard M, Dalby Salvig J, Secher NJ. Postpartum depression: Identification of women at risk. BJOG. 2000;107(10):1210-7. [PubMed: 11028570].

42. Grussu P, Quatraro RM. Prevalence and risk factors for a high level of postnatal depression symptomatology in Italian women: A sample drawn from ante-natal classes. Eur Psychiatry. 2009;24(5):327-33. doi: 10.1016/j.eurpsy.2009.01.006. [PubMed: 19328659].
43. Reubi D, Herrick C, Brown T. The politics of non-communicable diseases in the global South. Health Place. 2016;39:179-87. doi 10.1016/j.healthplace.2015.09.001. [PubMed: 26365886]. [PubMed Central: PMC4889786].

44. Wong J, Fisher J. The role of traditional confinement practices in determining postpartum depression in women in Chinese cultures: A systematic review of the English language evidence. J Affect Disord. 2009;116(3):161-9. doi: 10.1016/j.jad.2008.11.002. [PubMed: 19135261].

45. Martinez-Schallmoser L, Telleen S, MacMullen NJ. The effect of social support and acculturation on postpartum depression in Mexican American women. J Transcult Nurs. 2003;14(4):329-38. doi: 10.1177/1043659603257162. [PubMed: 14535154].

46. Pham D, Cormick G, Amyx MM, Gibbons L, Doty M, Brown A, et al. Factors associated with postpartum depression in women from low socioeconomic level in Argentina: A hierarchical model approach. J Affect Disord. 2018;227:731-8. doi: 10.1016/j.jad.2017.11.091. [PubMed: 29179143]. [PubMed Central: PMC5805649].

47. Miyake Y, Tanaka K, Sasaki S, Hirota Y. Employment, income, and education and risk of postpartum depression: The Osaka maternal and child health study. J Affect Disord. 2011;130(1-2):133-7. doi 10.1016/j.jad.2010.10.024. [PubMed: 21055825].

48. Goyal D, Gay C, Lee KA. How much does low socioeconomic status increase the risk of prenatal and postpartum depressive symptoms in first-time mothers? Womens Health Issues. 2010;20(2):96-104. doi: 10.1016/j.whi.2009.11.003. [PubMed: 20133153]. [PubMed Central: PMC2835803].

49. Song D, Sands RG, Wong YL. Utilization of mental health services by low-income pregnant and postpartum women on medical assistance. Women Health. 2004;39(1):1-24. doi: 10.1300/J013v39n01_01. [PubMed: $15002880]$. 